\title{
cara 0 potencial na integração do agente controlador de endemia na Estratégia Saúde da Família
}

\section{Potential integration of endemic diseases agent in the Family Health Strategy \\ El potencial en la integración del agente de controle a las endemias en la Estrategia de Salud de la Familia}

\author{
Eduardo Dias Wermelinger ${ }^{1}$ - (1) orcid.org/0000-0003-1926-4789 \\ Aldo Pacheco Ferreira' ${ }^{1}$ - D orcid.org/0000-0002-7122-5042 \\ 'Fundação Oswaldo Cruz, Escola Nacional de Saúde Pública, Rio de Janeiro, RJ, Brasil
}

Prezada editora,

Artigo publicado no n. 1 do vol. 30 deste periódico ${ }^{1}$ abordou a integração do agente de controle de endemia na Estratégia Saúde da Família (ESF) no combate ao Aedes aegypti, apontando para a necessidade de realizar ajustes nessa integração. No sentido de contribuir na reflexão acerca desses ajustes, trazemos algumas ponderações.

A assimilação de conhecimentos adequados não necessariamente reverte em ações efetivas na eliminação dos criadouros; ${ }^{2}$ essa dimensão deve ser considerada, mas reforça a pertinência e relevância da interação dos agentes de endemia na ESF. É importante considerar as dificuldades - até mesmo dos agentes - para alcançar os criadouros urbanos do Aedes aegypti, assim como notar as limitações comuns dos cidadãos (doenças, obesidade, idade, deficiências, fobias, entre outras) que thes dificultam ou impossibilitam alcançar e eliminar muitos dos criadouros. ${ }^{2}$ A culpabilização individual deve ser evitada, privilegiando-se o planejamento de estratégias efetivas que contornem as limitações em cada contexto. ${ }^{2}$

Seria conveniente refletir sobre a pertinência de capacitar as equipes com novas habilidades, em especial direcionadas à promoção de ações colaborativas e cooperativas, ${ }^{2}$ a fim de se contornarem os obstáculos sociais e ambientais e se propiciar a interação com outros serviços, como a coleta de lixo, e com diferentes profissionais, a exemplo de assistentes sociais.

Idealmente, é estratégico propor uma atuação abrangente no combate aos vetores, porque o mesmo ambiente urbano onde prolifera 0 Aedes aegypti também pode ser propício à proliferação de outros importantes vetores para a saúde pública, como pernilongos, moscas, baratas e ratos. 


\section{Referências}

1. Pereira GA, Picoli RP, Cazola LHO. Integração do agente de combate à endemias na Estratégia Saúde da Família, Campo Grande, Mato Grosso do Sul, 2017. Epidemol Serv Saude. 2021; 30(1):e2019500. doi: http://dx.doi.org/10.1590/ s1679-49742021000100018.
2. Wermelinger ED, Salles ICM. O sujeito preventivo das doenças transmitidas pelo Aedes aegyti nas campanhas publicitárias: obrigação, culpabilização e álibi para a responsabilidade do poder público. Physis. 2018;28(4): e280401. doi: https://doi. org/10.1590/S0103-73312018280401.

Recebido em 12/04/2021

Aprovado em 21/07/2021 